\title{
Corrosion inhibition of mild steel in hydrochloric acid solution using fatty acid derivatives
}

\begin{abstract}
The inhibitive actions of fatty acid derivatives namely palmitate hydrazide (PH), N-ethylidene palmitate hydrazide $(\mathrm{EPH})$ and N-phenylmethylidene palmitate hydrazide (PPH) on mild steel in $1 \mathrm{M}$ hydrochloric acid were investigated using open circuit potential, linear polarisation and electrochemical impedance spectroscopy techniques. It was observed that the percentage of inhibition efficiency $(\eta \%)$ increased with increasing concentrations of inhibitor and temperature of test medium. The maximum $\eta \%$ approaches $85 \%$ in the presence of $200 \mathrm{mg}$ litre-1 of inhibitors EPH and PPH at $308 \pm 1 \mathrm{~K}$. The inhibitor efficiencies were found to be in the following order: $\mathrm{PPH}>\mathrm{EPH}>\mathrm{PH}$. The adsorption of these inhibitors on mild steel surface obeys Langmuir adsorption isotherm. They act as mixed-type inhibitors. Scanning electron microscopy-energy dispersive X-ray (SEM-EDX) was also carried out on polished mild steel coupons and those immersed in the test medium with the absence and presence of $200 \mathrm{mg}$ litre1 of the inhibitors studied.
\end{abstract}

Keyword: Corrosion inhibition; Fatty acid derivatives; Mild steel; Schiff base 